\title{
Metformin Exerts Antiproliferative and Anti-metastatic Effects Against Cholangiocarcinoma Cells by Targeting STAT3 and NF-kB
}

\author{
CHARUPONG SAENGBOONMEE ${ }^{1,3}$, WUNCHANA SEUBWAI ${ }^{2,3}$, UBON CHA'ON $^{1,3}$, \\ KANLAYANEE SAWANYAWISUTH ${ }^{1,3}$, SOPIT WONGKHAM ${ }^{1,3}$ and CHAISIRI WONGKHAM ${ }^{1,3}$ \\ ${ }^{1}$ Department of Biochemistry, Faculty of Medicine, Khon Kaen University, Khon Kaen, Thailand; \\ ${ }^{2}$ Department of Forensic Medicine, Faculty of Medicine, Khon Kaen University, Khon Kaen, Thailand; \\ ${ }^{3}$ Liver Fluke and Cholangiocarcinoma Research Center, Faculty of Medicine, \\ Khon Kaen University, Khon Kaen, Thailand
}

\begin{abstract}
Background/Aim: Cholangiocarcinoma (CCA) is an aggressive cancer for which standard treatments are still ineffective. This study demonstrated the antiproliferative and anti-metastatic activity of metformin, an anti-diabetic drug, in CCA cells. Materials and Methods: Cell proliferation, migration/invasion and anoikis resistance were determined. The underlying mechanisms were identified using western blotting and immunocytofluorescence. Results: Metformin significantly suppressed proliferation of CCA cells in a dose-and timedependent manner, regardless of glucose present in the medium. A low dose of metformin significantly increased anoikis and inhibited migration/ invasion of CCA cells that was in concert with the decrease of vimentin, matrix metalloproteinase (MMP)2 and -7. Activation of 5' adenosine monophosphate-activated protein kinase $(A M P K)$ by phosphorylation together with suppression of nuclear translocation of signal transducer and activator of transcription 3 (STAT3) and nuclear factor-kappa $B(N F-k B)$ were the underlying mechanisms for these effects. Conclusion: Metformin is a potent antiproliferative and antimetastatic agent against human CCA cells. These findings encourage the repurposing of metformin in clinical trials to improve CCA treatment.
\end{abstract}

This article is freely accessible online.

Correspondence to: Chaisiri Wongkham, Ph.D., Department of Biochemistry, Faculty of Medicine, Khon Kaen University, Khon Kaen 40002, Thailand. Tel/Fax:+6643 348386, e-mail: chaisiri@kku.ac.th and Wunchana Seubwai, Ph.D., Department of Forensic Medicine,Faculty of Medicine,Khon Kaen University, Khon Kaen 40002, Thailand. Tel/Fax: +6643 202859, e-mail: wunchanas@yahoo.com

Key Words: Metformin, cholangiocarcinoma, proliferation, STAT3, NF-kB.
Cholangiocarcinoma (CCA) is the most common type of liver cancer after hepatocellular carcinoma worldwide. The incidence of CCA varies geographically: It is considered low in Western countries, but it is relatively high in the East and Southeast Asia. A high incidence of CCA has been noted in the Northeast of Thailand and infection with the liver fluke, Opisthorchis viverrini has been shown to be a strong risk factor for $\mathrm{CCA}$ in this region (1). Primary sclerosing cholangitis, hepatolithiasis, and hepatitis B virus infection, however, are the documented risk factors for $\mathrm{CCA}$ in Western countries $(2,3)$. CCA is a lethal type of cancer since early diagnosis is rarely possible. Most patients present at an inoperable advanced/metastatic stage. Chemotherapeutic and radiological therapies are alternative choices, but these treatments still have a low potential for curative purposes (4). The search goes on for additive treatments that might improve therapeutic outcome.

Development of a new pharmaceutical requires extensive research and development costs and time. Repositioning a drug that is already clinically used provides a way to shortcut the research and time required, and costs much less (5). Diabetes mellitus (DM) has been reported to be associated with risk and prognosis of many cancer types, including CCA $(6,7)$. The molecules that bridge DM and cancer have been shown to be insulin and a high blood glucose level (8-10). Repositioning an antidiabetic compound that appears to have great potential for cancer prevention and as a cure provides a rare opportunity. Metformin is such a drug.

Metformin is a widely studied drug for its potential for cancer treatment even though it is primarily used as a first-line treatment for type $2 \mathrm{DM}$. Metformin indirectly activates AMPactivated protein kinase (AMPK) by inhibiting the activity of mitochondrial complex I, resulting in an increased cellular AMP/ATP ratio. Activated AMPK plays an important role as a cellular energy sensor by promoting glycolysis and inhibiting 
gluconeogenesis. Apart from its function in energy metabolism, AMPK is able to interact with several signaling pathways and transcription factors such as phosphoinositide-3-phosphate/ protein kinase B (PI3K/AKT), Janus kinase/signal transducer and activator of transcription (JAK/STAT), nuclear factorkappa $\mathrm{B}(\mathrm{NF}-\mathrm{kB})$ and the mammalian target of rapamycin (mTOR). The attempt to repurpose a drug for CCA, in this instance metformin, is a potential way to find an improvement for CCA treatment. An epidemiological study in the United States showed that metformin significantly reduced risk of CCA in patients with DM (11). The potential for repurposing metformin for cancer treatment has been reviewed (5). To date, 243 clinical trials of metformin as cancer treatment have been registered at https://www.clinicaltrials.gov. Metformin, however, is still at the preclinical stage for some cancer types, including CCA $(12,13)$.

In the present study, the effects of metformin on the proliferation and progression of liver fluke-associated CCA cells were examined. The effects of metformin on the metastatic potential, namely migration, invasion and anoikis resistance of CCA cells are reported. The molecular mechanisms by which metformin affected CCA cells were elucidated. The demonstrated effects of metformin on CCA cells in the present study should further encourage clinical trials to improve the treatment of CCA.

\section{Materials and Methods}

Chemicals and antibodies. Metformin (1, 1-dimethylbiguanide hydrochloride) was purchased from Sigma-Aldrich (St. Louis City, MO, USA) and dissolved in sterile distilled water. Primary antibodies to p-AMPK $\alpha$ (T183/172), AMPK, p-RB (S249/T252), Rb, Cyclin D1, MMP2, MMP7, NF-kB (p65) were purchased from Santa Cruz Biotechnology (Santa Cruz, CA, USA), anti-p21 was from Cell Signaling, (Danvers, MA, USA), anti-vimentin from Abcam (Cambridge, UK), and anti-actin from Sigma. The secondary antibodies for western blots were goat anti-mouse and donkey antirabbit from GE Healthcare (Buckinghamshire, UK), and rabbit antigoat from Dako (Carpinteria, CA, USA). The secondary antibodies for the immunocytofluorescent study were fluorescein isothyocyanate (FITC)-conjugated goat anti-rabbit (Santa Cruz Biotechnology) and Alexa Fluor 568-conjugated goat anti-rabbit (Invitrogen, Eugene, OR, USA). Hoechst 33342 was purchased from Invitrogen.

Cell lines. CCA cell lines, namely KKU-055, KKU-100, KKU-213 and KKU-214, were originally established from primary cultures of liver fluke associated CCA tissues from Thai patients and obtained from the Japanese Collection of Research Bioresources Cell Bank, Osaka, Japan. Cells were maintained in Dulbecco's modified Eagle's medium (DMEM)-high glucose (HG; $25 \mathrm{mM}$ ) or normal glucose (NG; $5.6 \mathrm{mM}$ ) supplemented with $10 \%$ fetal bovine serum and $1 \%$ antibiotic-antimycotic (all from Invitrogen). Cells were incubated at $37^{\circ} \mathrm{C}$ with $5 \% \mathrm{CO}_{2}$, in a humidified incubator and passaged when confluence reached $80 \%$.

Proliferation assay. CCA cells were seeded into 96 -well plates at $3 \times 10^{3}$ cells/well and cultured overnight in a humidified incubator at $37^{\circ} \mathrm{C}$ with $5 \% \mathrm{CO}_{2}$. Cells were then treated with $5,10,20$, $40 \mathrm{mM}$ metformin for $48 \mathrm{~h}$ or for different times. The number of viable cells was determined using the 3-(4,5-dimethylthiazol-2-yl)2,5-diphenyltetrazolium bromide (MTT) assay as described in our previous study (14).

Migration and invasion assay. CCA cells were pretreated with $10 \mathrm{mM}$ metformin for $24 \mathrm{~h}$ prior to migration and invasion assays according to our previous report (14). Cells were allowed to migrate in the absence of metformin for $12 \mathrm{~h}$ for KKU-M213 and $24 \mathrm{~h}$ for KKUM214 cells. The invasion assay was performed using the same protocol as the migration assay except that the upper chamber was pre-coated with $50 \mu \mathrm{g} /$ well of Matrigel (BD Bioscience, Bedford, MA, USA)

Anoikis assay. CCA cells were suspended in a complete medium containing $0,10,20 \mathrm{mM}$ of metformin and then seeded into a 24well ultralow attachment plate (Corning, Lowell, MA, USA) which was coated with a neutral charge of hydrogel to prevent the adherence of cells. Cells $\left(5 \times 10^{4}\right.$ cells/well $)$ were then incubated in the non-adhered condition for $48 \mathrm{~h}$. Total cells in each well were collected, washed twice with PBS and treated with trypsin for 5 min to obtain a single-cell suspension. The numbers of viable and dead cells were determined using the trypan blue dye exclusion assay. Three independent experiments were performed with triplicated tests.

Western blot analysis for cell-cycle proteins. CCA cells were treated with $10,20,40 \mathrm{mM}$ metformin for $48 \mathrm{~h}$ whereas those for protein markers of metastasis were treated with $10 \mathrm{mM}$ metformin for $24 \mathrm{~h}$. Cells were lysed with NP-40 lysis buffer containing protease and phosphatase inhibitor cocktail (Roche, Mannheim, Germany). Cell lysates were prepared, subjected to sodium dodecyl sulphate -polyacrylamide gel electrophoresis and transferred to a Hybond $^{\mathrm{TM}}$-polyvinylidene fluoride (PVDF) membrane as mentioned previously (14). The membrane was probed with each primary antibody at $4^{\circ} \mathrm{C}$ overnight and with horseradish peroxidaseconjugated secondary antibody for $1 \mathrm{~h}$ at room temperature. Signals were detected using an enhanced chemiluminescence prime western blotting detection kit (GE Healthcare) and the image was analyzed using Image Quant ${ }^{\mathrm{TM}}$ Imager (GE Healthcare).

Immunocytofluorescence analysis. CCA cells $\left(8 \times 10^{3}\right.$ cells/well $)$ were cultured in Matrigel pre-coated slide chambers overnight at $37^{\circ} \mathrm{C}$ with $5 \% \mathrm{CO}_{2}$. The cells were treated 10 and $20 \mathrm{mM}$ metformin for $24 \mathrm{~h}$. Immunofluorescent staining was performed and recorded as described previously (14). Fixed cells were incubated with 1:100 anti-STAT3 or anti-p65 antibodies at $4{ }^{\circ} \mathrm{C}$ overnight. Then, 1:200 FITC-conjugated secondary antibody for STAT3 or 1:200 Alexa Fluor 568-conjugated secondary antibody for p65 antibody and 1:10,000 of Hoechst 33342 were applied at room temperature for further $2 \mathrm{~h}$. The immunofluorescent images were captured and analyzed using Nikon NIS-Elements software (Nikon, Tokyo, Japan).

Statistical analysis. All quantitative data are reported as mean \pm SD. Triplicate tests for each experiment and at least two independent experiments were performed. The differences between two groups were compared using the two-tailed Student's $t$-test. A value of $p<0.05$ was considered as statistically significant. 

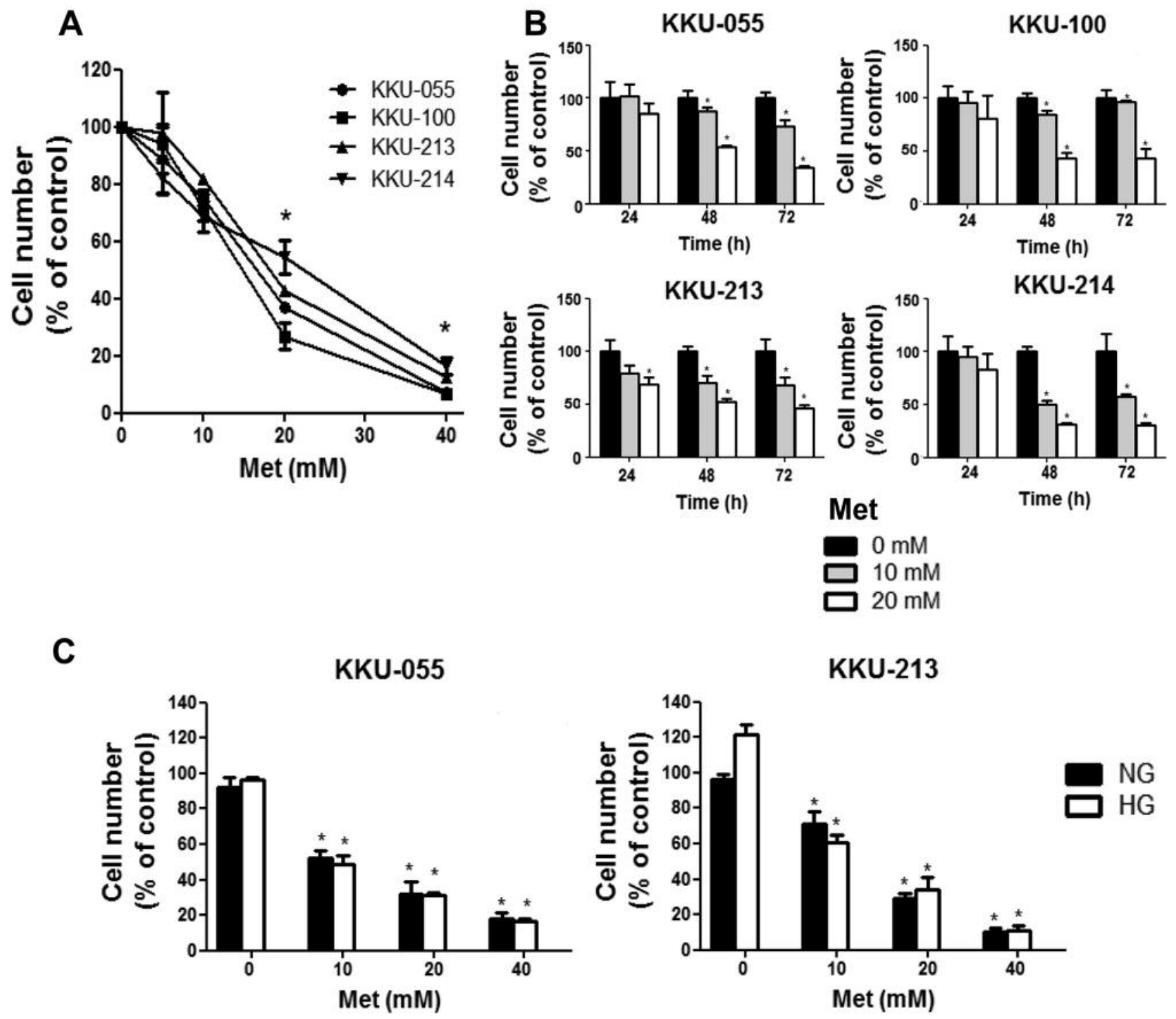

Figure 1. Metformin exerted an antiproliferative effect on cholangiocarcinoma (CCA) cell lines in a dose-and time-dependent manner. Cells were treated with different concentrations of metformin for different times and the viable cells were determined using the 3-(4,5-dimethylthiazol-2-yl)-2,5diphenyltetrazolium bromide (MTT) assay. A: Cells were cultured in the presence of 5, 10, 20 or $40 \mathrm{mM}$ metformin for 48 h. B: CCA cells were treated with 10 or $20 \mathrm{mM}$ metformin for 24, 48 and $72 \mathrm{~h}$. Data are mean $\pm S D$ of three independent experiments. *Significantly different from control of each time point, $p<0.05$. C: Metformin had similar growth inhibitory effects on CCA cells regardless of the glucose level in the medium. Data are the mean $\pm S D$ from triplicate assays from one of two independent experiments (*p<0.05). NG: Normal glucose; HG: high glucose; Met: metformin.

\section{Results}

Metformin suppressed proliferation of CCA cells regardless of glucose level. The effect of metformin on cell proliferation was first tested in four CCA cell lines cultured in medium with $10-40 \mathrm{mM}$ of metformin for $48 \mathrm{~h}$. The antiproliferative effect of metformin was observed in all CCA cell lines tested in a dose- (Figure 1A) and time- (Figure 1B) dependent manner. All CCA cell lines responded to metformin treatment in a similar manner, with a half-maximal inhibitory
Table I. The half-maximal inhibitory concentration $\left(I C_{50}\right)$ of metformin for cholangiocarcinoma cell lines after $48 \mathrm{~h}$ treatment.

\begin{tabular}{ll}
\hline Cell line & $\mathrm{IC}_{50}(\mathrm{mM})$ \\
\hline KKU-055 & $14.94 \pm 5.38$ \\
KKU-100 & $14.32 \pm 2.60$ \\
KKU-213 & $18.61 \pm 6.22$ \\
KKU-214 & $16.86 \pm 1.72$
\end{tabular}

The $\mathrm{IC}_{50}($ mean $\pm \mathrm{SD})$ was calculated from three independent experiments. 
A

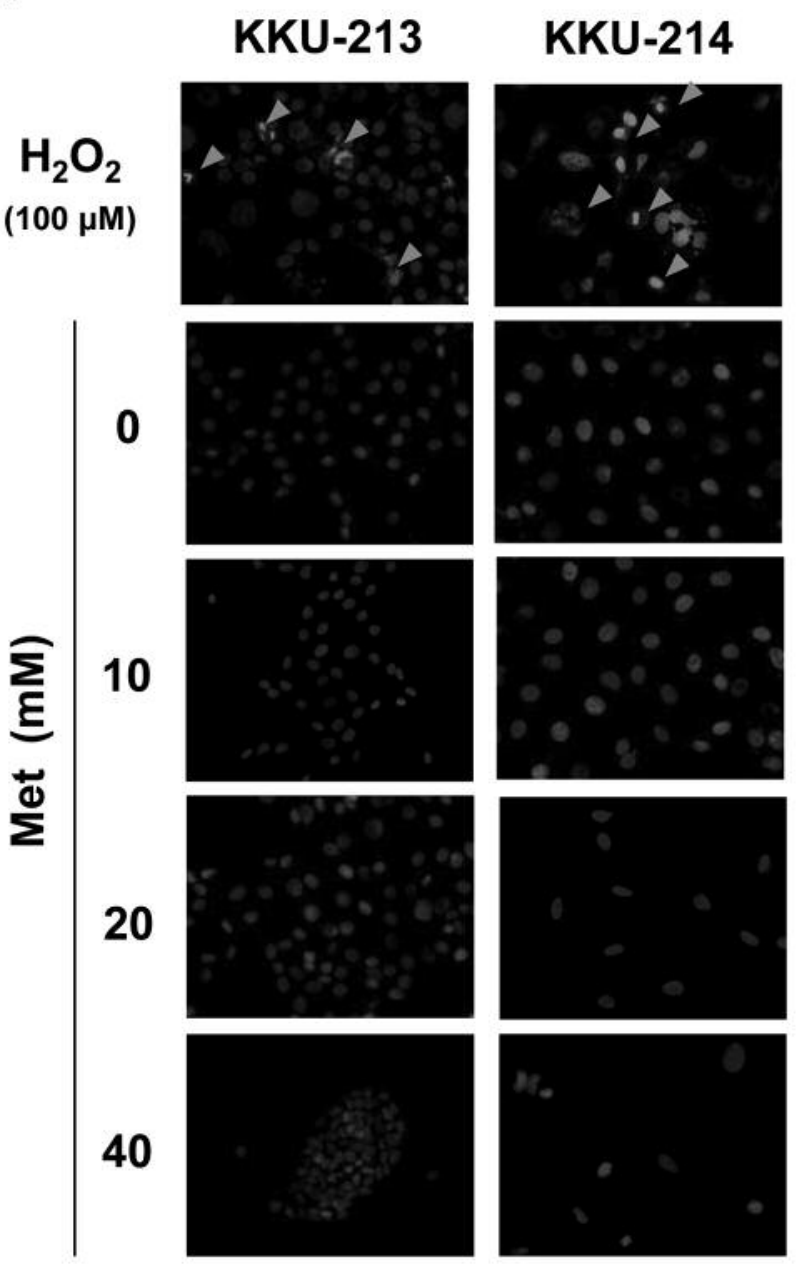

B
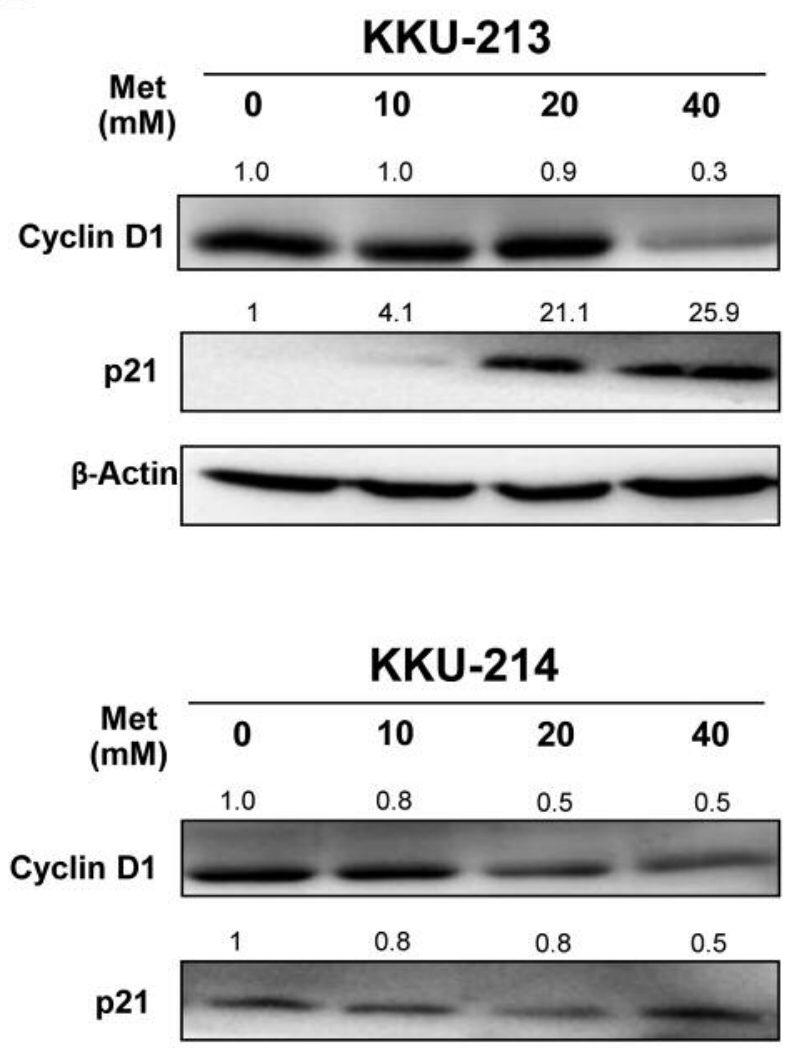

B-Actin

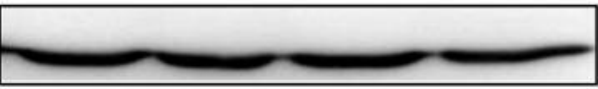

Figure 2. Metformin inhibited cholangiocarcinoma cell growth without induction of apoptosis. A: Hoechst staining was used to demonstrate nuclear morphology and chromatin condensation of DNA. Cells were treated with 10-40 mM of metformin for 48 h. No chromatin condensation was noted in control nor in metformin-treated cells. $\mathrm{H}_{2} \mathrm{O}_{2}(100 \mu \mathrm{M})$ was used as a positive control to illustrate the feature of apoptotic nuclei (indicated by arrows). B: Western blot analysis of cell-cycle regulatory proteins: cyclin D1 and p21. Quantification of each protein was performed using $\beta$-actin as an internal control and compared by designating expression of the untreated sample as 1. Data are representative of two independent experiments. Met: Metformin.

concentration $\left(\mathrm{IC}_{50}\right)$ that ranged from 14.3 to $18.6 \mathrm{mM}$ (Table I).

As DM and CCA seem to be associated, and metformin is generally used for diabetic patients who have chronic hyperglycemia, it was next tested as to whether the antiproliferative effect of metformin would be effective in patients with normal blood glucose. The antiproliferative effect of metformin was then tested in KKU-055 and KKU213 cells cultured in media with normal glucose or high glucose, in the presence or absence of metformin. The results showed that regardless of glucose concentration, metformin exhibited similar effects on growth inhibition in a dosedependent manner (Figure 1C).
As apoptotic cells were not observed in metformin-treated cells, it was hypothesized that the antiproliferative activity of metformin should be, partly, due to growth suppression rather than apoptosis induction. To demonstrate this, KKU-213 and KKU-214 cells were treated with different concentrations of metformin for $48 \mathrm{~h}$ and apoptotic cells were observed using Hoechst staining. Cells treated with $100 \mu \mathrm{M}$ hydrogen peroxide for $48 \mathrm{~h}$ were used as positive controls. As shown in Figure $2 \mathrm{~A}$, nuclear fragmentation and chromatin condensation were observed in the hydrogen peroxide-treated cells but were rarely observed in the cells treated with up to $40 \mathrm{mM}$ metformin.

To affirm the cytostatic effect of metformin, cell-cycle regulatory proteins, namely cylclin D1 and p21, were 
A
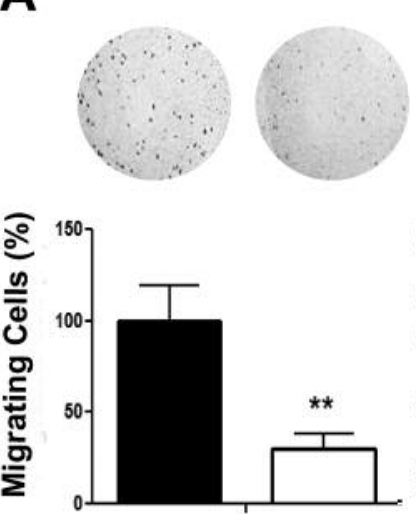

KKU-213

B
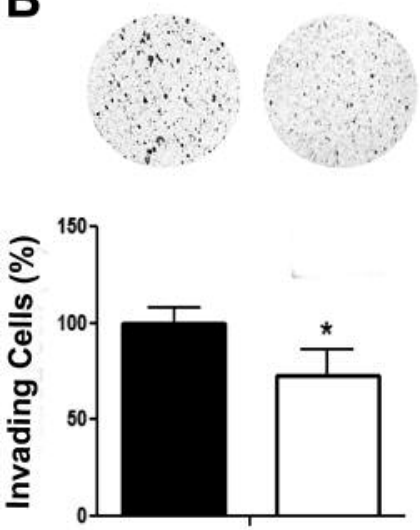

KKU-213
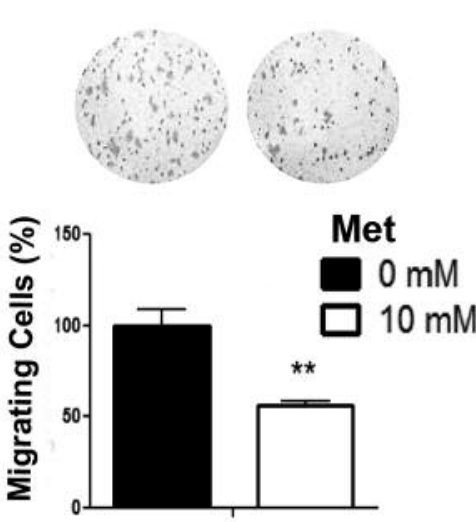

KKU-214
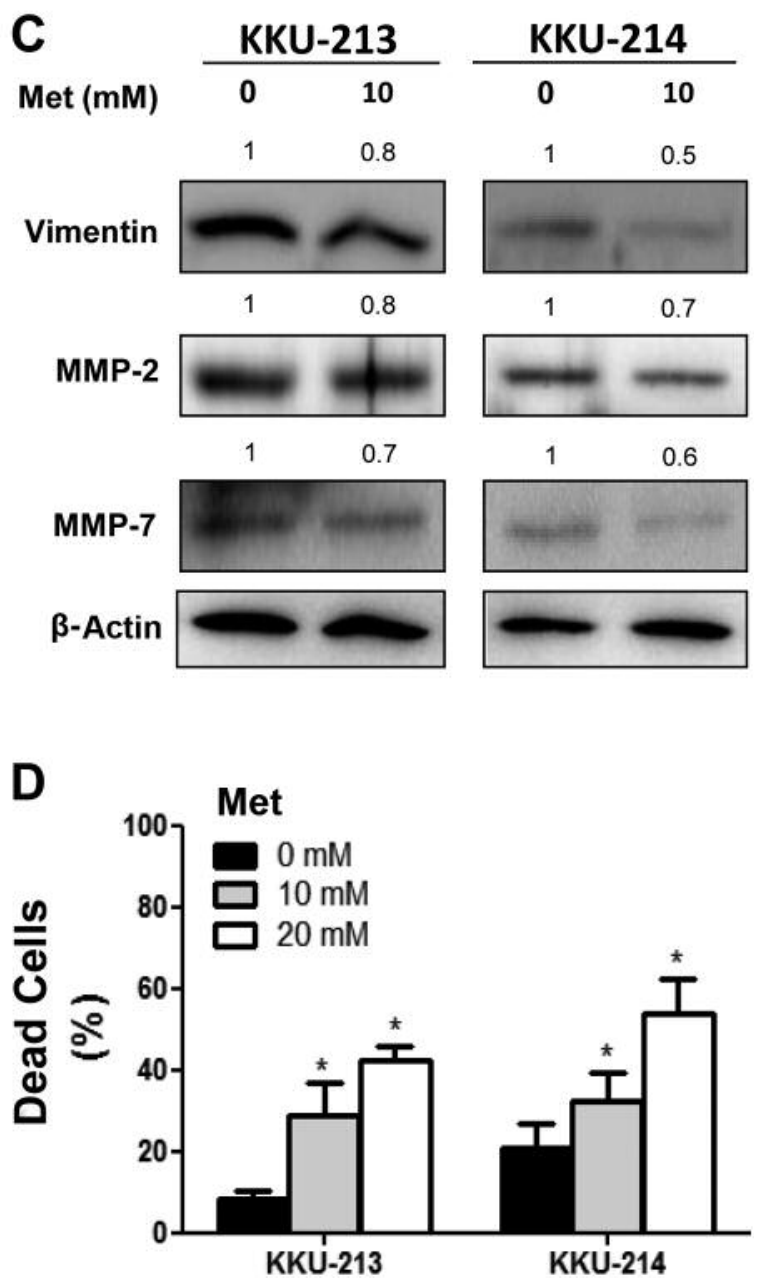

Figure 3. Metformin suppressed migration and invasion and induced anoikis of cholangiocarcinoma cells. KKU-213 and KKU-214 cells were pretreated with $10 \mathrm{mM}$ metformin for $24 \mathrm{~h}$ before being subjected to migration and invasion assays. Numbers of migrating (A) and invading (B) cells were counted and compared by assigning the controls a value of $100 \%$. Data are the mean $\pm S D$ of triplicates from one of two independent experiments. C: Western blots of vimentin, matrix metalloproteinase (MMP)-2 and -7. Quantification of each protein was performed using $\beta$-actin as an internal control and compared by designating expression of the untreated sample as 1.D: Anoikis resistance was assessed in the absence and presence of 10 or $20 \mathrm{mM}$ metformin for $48 \mathrm{~h}$. The number of dead cells was counted using the trypan blue dye exclusion assay. The data are representative of three independent experiments. ${ }^{*} p<0.05,{ }^{*} p<0.01$.

determined in cells treated with metformin for $48 \mathrm{~h}$. Compared to the untreated control cells, suppression of cyclin D1 and up-regulation of p21 were observed in CCA cells treated with increasing metformin concentrations (Figure 2B).

Low dose of metformin inhibited migration and invasion of CCA cells. CCA cells (KKU-213 and KKU-214) treated with $10 \mathrm{mM}$ metformin for $24 \mathrm{~h}$ were used to examine the effect of metformin on migration and invasion, as this concentration did not significantly affect growth of CCA cells. After $24 \mathrm{~h}$ of metformin treatment, cells were allowed to migrate in the absence of metformin for $12 \mathrm{~h}$ for KKU-
M213 and $24 \mathrm{~h}$ for KKU-M214. Metformin significantly reduced migrated cells to $30-50 \%$ and invaded cells to 50 $70 \%$ of the controls (Figure $3 \mathrm{~A}$ and $\mathrm{B}$ ). To explore the underlying mechanism, the expression levels of vimentin, MMP2 and MMP7 were determined using western blotting. As shown in Figure 3C, the expressions of vimentin, MMP2 and MMP7 were reduced in metformin-treated compared to control cells.

Metformin induced anoikis of CCA cells. Anoikis resistance or resistance to apoptosis in non-adherent conditions is a key property of cells that metastasize. 
Whether metformin can induce anoikis was next analyzed in CCA cells treated with 10 and $20 \mathrm{mM}$ metformin in a 24-well ultralow attachment plate for $48 \mathrm{~h}$. The total cells were harvested and the live $v s$. dead cells were determined using the trypan blue dye exclusion assay. As shown in Figure 3D, the basal percentage of dead cells induced by anoikis in the control cells was $10-20 \%$ of the total cell count. Metformin at 10 and $20 \mathrm{mM}$, however, significantly induced cell death by anoikis by up to 2 - to 3 -fold of that observed in the control cells.

Metformin activated AMPK. It is well documented that the conventional effect of metformin is through AMPK activation. The level of phosphorylation AMPK $\alpha$, a stimulatory subunit of AMPK, were determined in CCA cells treated with 10 and $20 \mathrm{mM}$ metformin for $48 \mathrm{~h}$. The western blot results demonstrated that p-AMPK $\alpha$ was increased 3- to 4-fold in metformin-treated cells while total AMPK $\alpha$ remained unaltered (Figure 4A). The ratio of p-AMPK $\alpha$ to AMPK $\alpha$ of both cell lines increased respectively in metformin-treated cells.

Metformin inhibited nuclear localization of $N F-k B$ and STAT3 without affecting their activations. Since the proteins affected by metformin treatment, as observed in this study, can be mediated by NF-kB and STAT3, important transcription factors in carcinogenesis and progression of CCA $(15,16)$, it was thus interesting to investigate whether metformin affected CCA cells via NF-kB or STAT3 pathways. The levels of NF-kB (p65) and STAT3 from whole-cell lysates of CCA cells treated with 10 and $20 \mathrm{mM}$ metformin for $48 \mathrm{~h}$ and the control cells were determined using western blots. Under metformin treatment, the expression of NF-kB (p65) slightly increased in KKU-213 cells, but was unaltered in KKU214 cells (Figure 4B). The western blots of STAT3 indicated that activation of STAT3 determined as the ratio of p-STAT3 (Y705 and S727) to STAT3 of the metformintreated cells did not differ from that of the control cells (Figure 4B).

As nuclear translocation is the crucial step for NF- $\mathrm{kB}$ and STAT3 activation, the localization of NF-kB (p65) and STAT3 was investigated using immunocytofluorescent staining and nuclei were localized using Hoechst staining. These generated bright blue signals for NF-kB p65 and bright purple signals for STAT3 when these were localized in the nucleus. As demonstrated in Figure 4C, the signals of NF-kB (p65) and STAT3 of almost all of the control cells were localized in the nucleus. In contrast, the signals of NF$\mathrm{kB}$ (p65) and STAT3 of the metformin-treated cells were mainly in the cytoplasm. These results indicate an inhibitory effect of metformin on the nuclear translocation of NF-kB (p65) and STAT3 in these CCA cell lines.

\section{Discussion}

Metastasis is a leading cause of death in all patients with cancer. It involves many biological processes such as invasion and migration to adjacent tissues and blood vessels, survival in the blood circulation and adhesion to secondary sites. Accumulated evidence suggests metformin to be a potential drug for suppressing the progression of tumors in many cancer types (5). The present study demonstrates the effects of metformin on the inhibitory mechanisms of Opisthorchis viverrini-associated CCA cells. Metformin exhibited dose- and time-dependent antiproliferative effects on CCA cells. In this study, it was additionally demonstrated for the first time that metformin at a non-antiproliferative dose significantly suppressed cell migration and invasion and the underlining mechanism was shown to be via the inhibition of nuclear translocation of NF-kB and STAT3.

In the current study, metformin effectively suppressed proliferation of CCA cell lines in a time- and dose-dependent manner. Metformin affected proliferation of CCA cells regardless of their chemo- or radioresistant behavior. The IC50 of all four CCA cell lines tested were similar in the range of 14.3-18.6 mM. KKU-100, a chemoresistant cell line (17) and KKU-055, a radioresistant clone (18), responded to metformin in the same manner. These effective doses were in agreement with reports on non-liver fluke-associated CCA $(12,19)$. Metformin also affected proliferation of CCA cells irrespectively of the glucose condition. DM has been considered as a common risk factor for various cancer types, including CCA (7). In addition, a high glucose condition can significantly enhance proliferation, migration and invasion of CCA cells (14). In the present study, metformin reduced proliferation not only of CCA cells cultured in normal glucose medium but also those cultured in high glucose medium. This information may imply an antitumor effect of metformin in patients with CCA regardless of diabetic condition.

Metformin inhibited proliferation of CCA cells without induction of apoptosis, as no obvious apoptotic cells were observed with metformin treatment. In addition, the western blot analyses indicated an increase of p21 and suppression of cyclin D1 in metformin-treated cells. These observations were in agreement with those previously reported in many cancer cell types $(13,20)$, including non-liver flukeassociated CCA cells $(12,19)$. In addition to cell-cycle regulatory proteins, the alteration of microRNA expression in metformin treated CCA cells was also noted $(12,21)$.

The present study also demonstrated, as far as we are aware of for the first time, the inhibitory effect of metformin on the metastatic potential of CCA cells. At low doses, metformin significantly suppressed migration and invasion, and induced anoikis of CCA cells. The molecular basis underlying these observations in metformin-treated cells was 
A
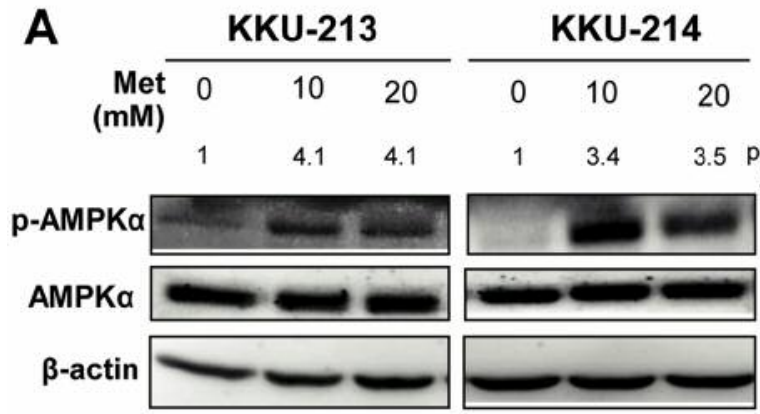

B
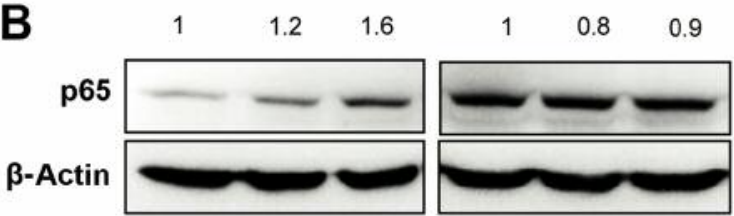

D
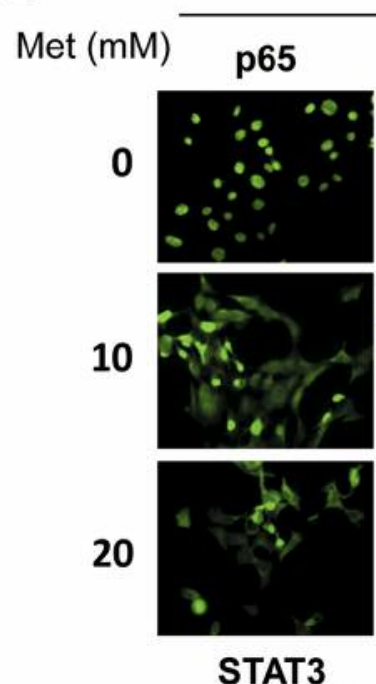

KKU-213

Hoechst
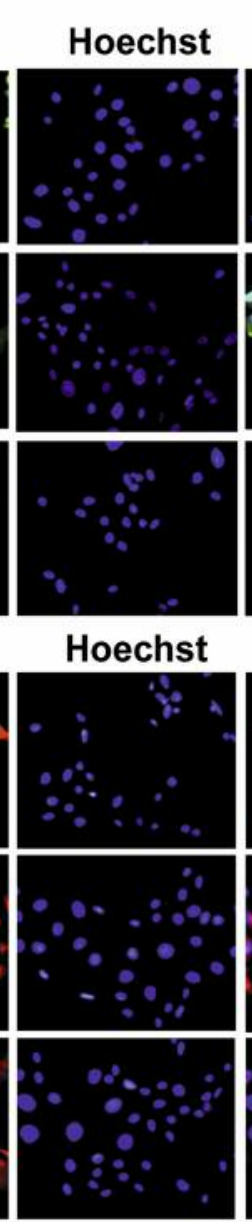

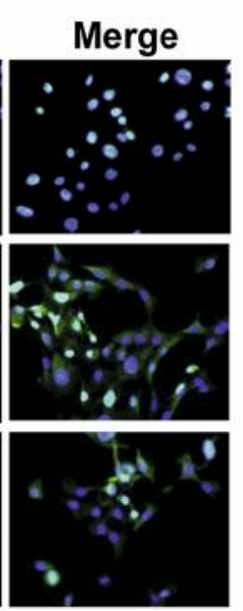

Merge

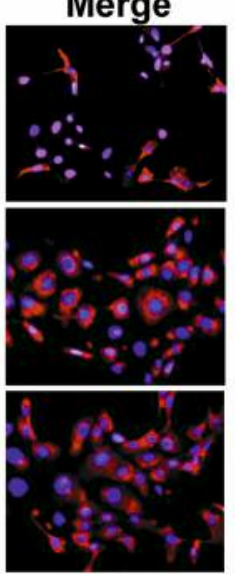

C

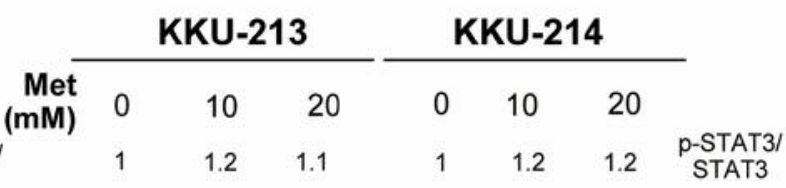
AMPKa p-STAT3
(Y705)

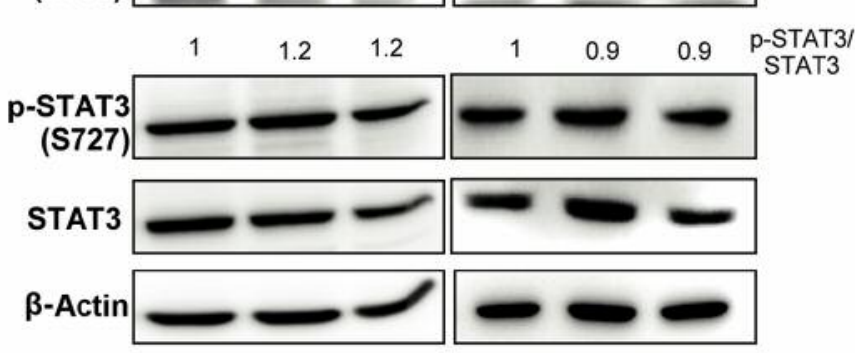

KKU-214
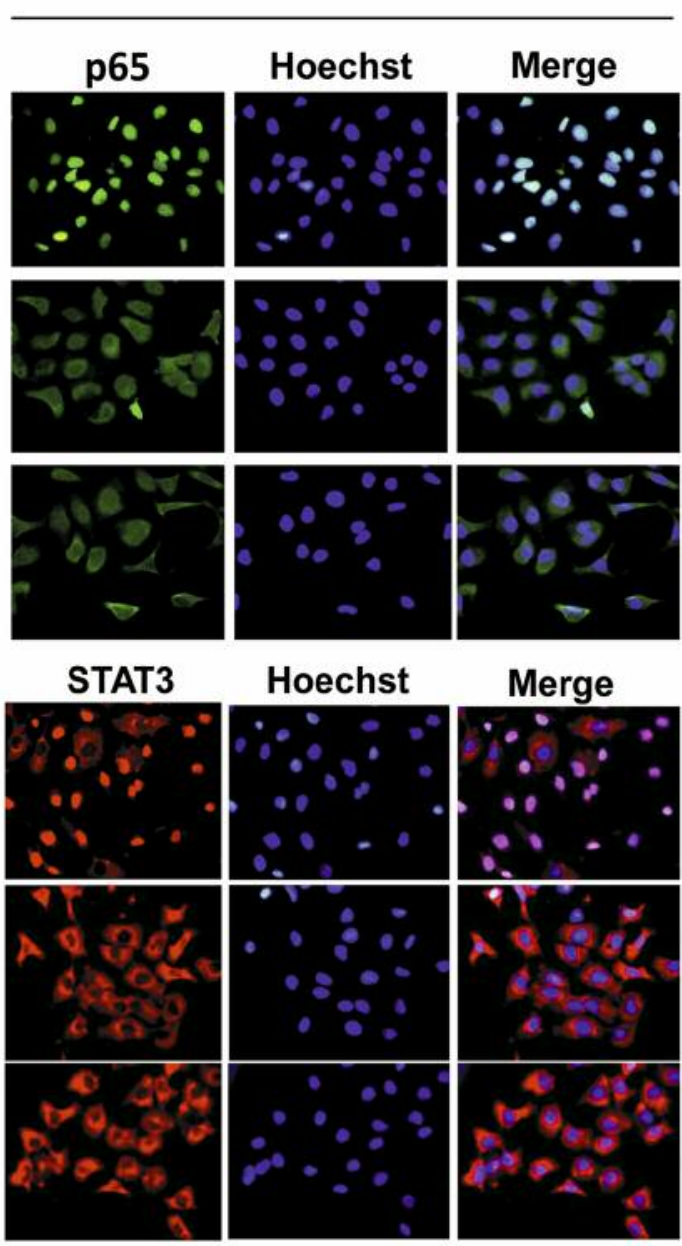

Figure 4. Metformin increased phosphorylated-5' adenosine monophosphate activated protein kinase (p-AMPK) and inhibited nuclear localization of nuclear factor-kappa $B(N F-k B)$ and signal transducer and activator of transcription 3 (STAT3). Cholangiocarcinoma cells were cultured in the

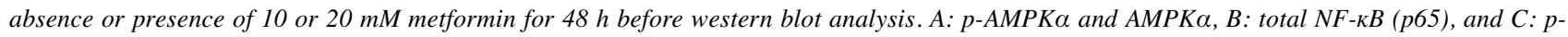
STAT3 (Y705 and S727) and STAT3. Quantification of each protein was performed using $\beta$-actin as an internal control and compared by designating expression of the untreated sample as 1.D: Cells were treated with 10 or $20 \mathrm{mM}$ metformin for $24 \mathrm{~h}$ and the cellular localizations of NF-kB (p65) (green) and STAT3 (red) were observed using immunocytofluorescent staining, x400 magnification. Met: Metformin. 
shown to be via suppression of vimentin, a marker of epithelial-mesenchymal transition related to cell motility, and anoikis, along with MMP2 and MMP7, essential enzymes for extracellular matrix degradation. These three markers are known to be under regulation of several key pathways, including STAT3 and NF-kB (22).

The conventional effect of metformin is trough the indirect activation of AMPK, however, there are many consequent transcription factors and signaling pathways activated/inactivated in responses to AMPK activation (5). Apart from AMPK, metformin exerts anticancer effects via multiple pathways, e.g. inhibition of the mTOR pathway in CCA (19), a decrease of forkhead box protein M1 (FOXM1) in leukemia (23), suppression of STAT3 activation in lung adenocarcinoma (24)and in triple-negative breast cancer (25), and inactivation of STAT3 and NF- $\mathrm{kB}$ in several cancer cell lines $(26,27)$.

In the present study, metformin activated the AMPK pathway as the level of p-AMPK in CCA cells actually increased in metformin-treated cells. To investigate the alternative pathways in response to metformin treatment, NF-kB and STAT3, the major transcription factors reported in development and progression of liver fluke-associated CCA $(15,16)$ were further examined. The results from western blots of whole-cell lysates showed no differences of p-STAT3 at both Y705 and S727 and the expression levels of p65 between the controls and the metformin-treated cells. This indicates that metformin had no effect on STAT3 phosphorylation and NF-kB expression. In contrast, the strong reduction of nuclear localization of STAT3 and p65 was observed in metformin-treated cells. Nuclear translocation of STAT3 and p65 is an important step to complete the activation of both transcriptional factors. Suppression of nuclear translocation of STAT3 and p65 may reduce the expression of their downstream regulated genes, e.g. vimentin, MMP2 and MMP7, as shown in this study. These assumptions are supported by several previous reports showing that inhibition of STAT3 and NF-kB activation using specific inhibitors significantly suppressed growth (14, 16), migration and invasion (28) of CCA cells.

The effects of metformin on the activation of STAT3 and the expression of NF- $\mathrm{kB}$ have been reported in many studies $(24,25,29-31)$. In the present study, these effects of metformin were not observed, however, the effects of metformin on nuclear translocation of STAT3 and NF-kB were pronounced. This effect of metformin on nuclear translocation of NF-kB (p65) was reported for the first time in the present study.

Taken together, the findings of this study indicate the additional effect of metformin on anti-metastatic properties of CCA cell lines. This action of metformin concurs with the observation of longer survival of patients with CCA with $\mathrm{DM}$ who received metformin than those without metformin treatment (21). The findings from this study are important in repurposing metformin as a drug of choice for CCA treatment, as metformin has several advantages in the treatment of CCA: i) Metformin affects CCA cells regardless of their etiology. Metformin effectively suppressed growth of liver fluke-associated and non-liver fluke-associated CCA. ii) Metformin effectively inhibited growth of CCA cells unrelated to the background of chemo- or radioresistant behavior: both a chemoresistant CCA cell line, KKU-100 and a radioresistant clone, KKU-055, were sensitive to metformin treatment in a similar manner. iii) A low dose of metformin can suppress metastatic activity of CCA cells. iv) Lastly, because metformin is already used in clinical practice, its safety and efficacy are known. Since CCA is a highly metastatic and highly recurrent cancer, the antimetastatic activity of metformin may be of an advantage for patients with CCA with metastasis. Further studies in animal models should be conducted to ensure the efficacy of the anticancer effect of metformin, either as a single drug or as a part of a combined treatment for CCA.

\section{Acknowledgements}

This work was co-supported by research grants from Khon Kaen University and the TRF Senior Research Scholar Grant, Thailand Research Fund to S. Wongkham (RTA5780012), a Khon Kaen University Research grant (KKU59) to U. Cha'on and a research grant from the Junior Science Talent Project (JSTP), National Science and Technology Development Agency (NSTDA) to C. Saengboonmee (JSTP-06-56-01E). C. Seangboonmee also thanks Faculty of Medicine, Khon Kaen University for the support of the BSc-PhD-MD program. We would like to thank Professor James A. Will for editing this article via the Faculty of Medicine Publication Clinic, Khon Kaen University, Thailand.

\section{References}

1 Vatanasapt V, Tangvoraphonkchai V, Titapant V, Pipitgool V, Viriyapap D and Sriamporn S: A high incidence of liver cancer in Khon Kaen Province, Thailand. Southeast Asian J Trop Med Public Health 21: 489-494, 1990.

2 Ben-Menachem T: Risk factors for cholangiocarcinoma. Eur J Gastroenterol Hepatol 19: 615-617, 2007.

3 Li M, Li J, Li P, Li H, Su T, Zhu R and Gong J: Hepatitis B virus infection increases the risk of cholangiocarcinoma: a metaanalysis and systematic review. J Gastroenterol Hepatol 27: 1561-1568, 2012.

4 Bhudhisawasdi V, Talabnin C, Pugkhem A, Khuntikeo N, Seow OT, Chur-in S, Pairojkul C and Wongkham S: Evaluation of postoperative adjuvant chemotherapy for intrahepatic cholangiocarcinoma patients undergoing R1 and R2 resections. Asian Pac J Cancer Prev 13(Suppl): 169-174, 2012.

5 Pernicova I and Korbonits M: Metformin--mode of action and clinical implications for diabetes and cancer. Nat Rev Endocrinol 10: 143-156, 2014.

6 Vigneri P, Frasca F, Sciacca L, Pandini G and Vigneri R: Diabetes and cancer. Endocr Relat Cancer 16: 1103-1123, 2009. 
7 Saengboonmee C, Seubwai W, Wongkham C and Wongkham S: Diabetes mellitus: Possible risk and promoting factors of cholangiocarcinoma: Association of diabetes mellitus and cholangiocarcinoma. Cancer Epidemiol 39: 274-278, 2015.

8 Belfiore A and Malaguarnera R: Insulin receptor and cancer. Endocr Relat Cancer 18: R125-147, 2011.

9 Garcia-Jimenez C, Garcia-Martinez JM, Chocarro-Calvo A and De la Vieja A: A new link between diabetes and cancer: enhanced WNT/ $\beta$-catenin signaling by high glucose. J Mol Endocrinol 52: R51-66, 2014.

10 Fedirko V, Lukanova A, Bamia C, Trichopolou A, Trepo E, Nothlings U, Schlesinger S, Aleksandrova K, Boffetta $P$, Tjonneland A, Johnsen NF, Overvad K, Fagherazzi G, Racine A, Boutron-Ruault MC, Grote V, Kaaks R, Boeing H, Naska A, Adarakis G, Valanou E, Palli D, Sieri S, Tumino R, Vineis P, Panico S, Bueno-de-Mesquita HB, Siersema PD, Peeters PH, Weiderpass E, Skeie G, Engeset D, Quiros JR, Zamora-Ros R, Sanchez MJ, Amiano P, Huerta JM, Barricarte A, Johansen D, Lindkvist B, Sund M, Werner M, Crowe F, Khaw KT, Ferrari P, Romieu I, Chuang SC, Riboli E and Jenab M: Glycemic index, glycemic load, dietary carbohydrate and dietary fiber intake and risk of liver and biliary tract cancers in Western Europeans. Ann Oncol 24: 543-553, 2013.

11 Chaiteerakij R, Yang JD, Harmsen WS, Slettedahl SW, Mettler TA, Fredericksen ZS, Kim WR, Gores GJ, Roberts RO, Olson JE, Therneau TM and Roberts LR: Risk factors for intrahepatic cholangiocarcinoma: association between metformin use and reduced cancer risk. Hepatology 57: 648-655, 2013.

12 Fujimori T, Kato K, Fujihara S, Iwama H, Yamashita T, Kobayashi K, Kamada H, Morishita A, Kobara H, Mori H, Okano K, Suzuki Y and Masaki T: Antitumor effect of metformin on cholangiocarcinoma: In vitro and in vivo studies. Oncol Rep 34: 2987-2996, 2015.

13 Cai X, Hu X, Tan X, Cheng W, Wang Q, Chen X, Guan Y, Chen $C$ and Jing $X$ : Metformin induced AMPK activation, $G_{0} / G_{1}$ phase cell cycle arrest and the inhibition of growth of esophageal squamous cell carcinomas in vitro and in vivo. PLoS One 10: e0133349, 2015.

14 Saengboonmee C, Seubwai W, Pairojkul C and Wongkham S: High glucose enhances progression of cholangiocarcinoma cells via STAT3 activation. Sci Rep 6: 18995, 2016.

15 Dokduang H, Techasen A, Namwat N, Khuntikeo N, Pairojkul C, Murakami Y, Loilome W and Yongvanit P: STATs profiling reveals predominantly-activated STAT3 in cholangiocarcinoma genesis and progression. J Hepatobiliary Pancreat Sci 21: 767776, 2014

16 Seubwai W, Wongkham C, Puapairoj A, Khuntikeo N, Pugkhem A, Hahnvajanawong C, Chaiyagool J, Umezawa K, Okada S and Wongkham S: Aberrant expression of NF-kB in liver fluke associated cholangiocarcinoma: implications for targeted therapy. PLoS One 9: e106056, 2014.

17 Tepsiri N, Chaturat L, Sripa B, Namwat W, Wongkham S, Bhudhisawasdi V and Tassaneeyakul W: Drug sensitivity and drug resistance profiles of human intrahepatic cholangiocarcinoma cell lines. World J Gastroenterol 11: 2748-2753, 2005.

18 Hematulin A, Sagan D, Sawanyawisuth K, Seubwai W and Wongkham S: Association between cellular radiosensitivity and $\mathrm{G}_{1} / \mathrm{G}_{2}$ checkpoint proficiencies in human cholangiocarcinoma cell lines. Int J Oncol 45: 1159-1166, 2014.
19 Ling S, Feng T, Ke Q, Fan N, Li L, Li Z, Dong C, Wang C, Xu F, Li Y and Wang L: Metformin inhibits proliferation and enhances chemosensitivity of intrahepatic cholangiocarcinoma cell lines. Oncol Rep 31: 2611-2618, 2014.

20 Quattrini I, Conti A, Pazzaglia L, Novello C, Ferrari S, Picci P and Benassi MS: Metformin inhibits growth and sensitizes osteosarcoma cell lines to cisplatin through cell-cycle modulation. Oncol Rep 31: 370-375, 2014.

21 Jiang X, Ma N, Wang D, Li F, He R, Li D, Zhao R, Zhou Q, Wang Y, Zhang F, Wan M, Kang P, Gao X and Cui Y: Metformin inhibits tumor growth by regulating multiple miRNAs in human cholangiocarcinoma. Oncotarget 6: 3178-3194, 2015.

22 Bollrath J and Greten FR: IKK/NF-kappaB and STAT3 pathways: central signalling hubs in inflammation-mediated tumour promotion and metastasis. EMBO Rep 10: 1314-1319, 2009.

23 Zhang B, Liu LL, Mao X and Zhang DH: Effects of metformin on FOXM1 expression and on the biological behavior of acute leukemia cell lines. Mol Med Rep 10: 3193-3198, 2014.

24 Zhao Z, Cheng X, Wang Y, Han R, Li L, Xiang T, He L, Long $\mathrm{H}$, Zhu B and He Y: Metformin inhibits the IL-6-induced epithelial-mesenchymal transition and lung adenocarcinoma growth and metastasis. PLoS One 9: e95884, 2014.

25 Deng XS, Wang S, Deng A, Liu B, Edgerton SM, Lind SE, Wahdan-Alaswad R and Thor AD: Metformin targets Stat 3 to inhibit cell growth and induce apoptosis in triple-negative breast cancers. Cell Cycle 11: 367-376, 2012.

26 Hirsch HA, Iliopoulos D and Struhl K: Metformin inhibits the inflammatory response associated with cellular transformation and cancer stem cell growth. Proc Natl Acad Sci USA 110: 972977, 2013.

27 Tan XL, Bhattacharyya KK, Dutta SK, Bamlet WR, Rabe KG, Wang E, Smyrk TC, Oberg AL, Petersen GM and Mukhopadhyay D: Metformin suppresses pancreatic tumor growth with inhibition of NFKB/STAT3 inflammatory signaling. Pancreas 44: 636-647, 2015.

28 Aneknan P, Kukongviriyapan V, Prawan A, Kongpetch S, Sripa B and Senggunprai L: Luteolin arrests cell cycling, induces apoptosis and inhibits the JAK/STAT3 pathway in human cholangiocarcinoma cells. Asian Pac J Cancer Prev 15: 5071-5076, 2014

29 Lin CC, Yeh HH, Huang WL, Yan JJ, Lai WW, Su WP, Chen HH and Su WC: Metformin enhances cisplatin cytotoxicity by suppressing signal transducer and activator of transcription-3 activity independently of the liver kinase B1-AMP-activated protein kinase pathway. Am J Respir Cell Mol Biol 49: 241-250, 2013.

30 Kim HG, Hien TT, Han EH, Hwang YP, Choi JH, Kang KW, Kwon KI, Kim BH, Kim SK, Song GY, Jeong TC and Jeong HG: Metformin inhibits P-glycoprotein expression via the NFkappaB pathway and CRE transcriptional activity through AMPK activation. Br J Pharmacol 162: 1096-1108, 2011.

$31 \mathrm{Gu}$ J, Ye S, Wang S, Sun W and Hu Y: Metformin inhibits nuclear factor- $\mathrm{kB}$ activation and inflammatory cytokines expression induced by high glucose via adenosine monophosphate-activated protein kinase activation in rat glomerular mesangial cells in vitro. Chin Med J 127: 1755-1760, 2014.

Received November 4, 2016

Revised November 25, 2016 Accepted November 29, 2016 